\title{
Histopathological study of endometrium in abnormal uterine bleeding
}

\author{
Bhatta $\mathrm{S}^{1}$, Sinha $\mathrm{AK}^{2}$ \\ ${ }^{I}$ Department of Pathology, KIST Medical College, Lalitpur, Nepal \\ ${ }^{2}$ Department of Pathology, B.P Koirala Institute of Health Sciences, Dharan, Nepal
}

\section{Keywords: \\ Abnormal uterine bleeding; \\ Endometrium; \\ Histopathology}

\begin{abstract}
Background: Histopathological evaluation of endometrial samples is essential in the workup of abnormal uterine bleeding. This study was carried out to evaluate patterns of endometrial histological findings in women with abnormal uterine bleeding and to correlate histopathological findings with clinical features.

Materials and Methods: One hundred and twenty two patients with diagnosis of abnormal uterine bleeding underwent endometrial sampling. The slides stained with Hematoxylin and Eosin stain were studied.

Results: The predominant endometrial histopathological finding was proliferative endometrium 32 cases (26.23\%) followed by simple hyperplasia without atypia 22 cases $(18.03 \%)$. Malignant lesions were more common in patients more than 40 years of age and comprised of 7 cases $(5.74 \%)$ of all cases. Atrophic endometrium was most common finding in postmenopausal bleeding 8 cases $(28.6 \%)$ followed by endometrial carcinoma 5 cases $(17.9 \%)$.

Conclusion: Histopathological examination of endometrium should be done generously in women presenting with abnormal uterine bleeding especially after the age of 40 years to rule out malignant pathology.
\end{abstract}

\section{INTRODUCTION}

Abnormal uterine bleeding (AUB) is defined as changes in frequency of menstruation, duration of flow or amount of blood loss. ${ }^{1}$ Several terms are popularly used to describe patterns of AUB. Menorrhagia refer to bleeding occurring at normal intervals (21 to 35) days but with heavy flow ( $>80$ $\mathrm{ml}$ ) or duration ( $>7$ days). Metrorrhagia is bleeding of any amount which is acyclical and which occurs irregularly or continuously in between normal cycles. Bleeding occurring at irregular, noncyclic intervals and with heavy flow

\section{Correspondence:}

Dr. Sushama Bhatta, MD

Department of Pathology, KIST Medical College and Teaching Hospital

Lalitpur, Nepal

E-mail:sushmabhatta@gmail.com
$(>80 \mathrm{ml}$ ) or duration ( $>7$ days) is called menometrorrhagia. Polymenorrhoea is cyclical bleeding which is normal in amount but which occurs at too frequent intervals of less than 21 days. Oligomenorrhea describes bleeding occurring at intervals greater than 35 days. Postmenopausal bleeding (PMB) is bleeding recurring in a menopausal woman at least one year after cessation of cycles. Dysfunctional uterine bleeding (DUB) is diagnosed after exclusion of pregnancy or pregnancy-related disorders, medications, iatrogenic causes, obvious genital tract pathology, and systemic conditions. ${ }^{2}$

Abnormal uterine bleeding can be caused by a wide variety of disorders. In women of child bearing age causes such as pregnancy complications, medications, systemic 
conditions and obvious genital tract pathology have to be ruled out. In women of child bearing age who are at high risk for endometrial cancer, the initial evaluation includes endometrial biopsy. ${ }^{2}$ The causes of bleeding in elderly women are hormonal and more importantly local pathology including malignancy, benign tumours and infections. While DUB is responsible for most cases of abnormal uterine bleeding in the adolescent age group, the incidence of structural pathology increases in other age groups. Endometrial malignancy is an important cause of menstrual disorder even though it is rare. Overall the incidence of endometrial cancer is 14.3 per 100,000 women years and it is even less common among premenopausal women. ${ }^{3,4}$ AUB after age of 40 years requires further evaluation to exclude endometrial polyp, hyperplasia, fibroid or carcinoma. ${ }^{5}$ This study was carried out to evaluate the patterns of endometrial histological findings in women with AUB and to correlate these findings with clinical features.

\section{MATERIALS AND METHODS}

This prospective study included 122 patients over 15 years of age with clinical diagnosis of AUB during one year

Table 1: Histopathological diagnosis of endometrial biopsy

\begin{tabular}{lcc}
\hline Histopathological diagnosis & No of patients & Percentage \\
\hline Proliferative & 32 & 26.23 \\
$\begin{array}{l}\text { Simple hyperplasia without } \\
\text { atypia }\end{array}$ & 22 & 18.03 \\
Secretory & 20 & 16.39 \\
Atrophic & 9 & 7.38 \\
Disordered proliferative & 8 & 6.56 \\
Chronic endometritis & 8 & 6.56 \\
Unsatisfactory & 8 & 6.56 \\
Carcinoma & 7 & 5.74 \\
Irregular & 5 & 4.10 \\
Polyp & 3 & 2.46 \\
\hline Total & 122 & 100 \\
\hline
\end{tabular}

period from June 2004 to May 2005 at B.P Koirala Institute of Health Sciences. Patients who were on hormonal therapy, bleeding related to pregnancy complications or cervical pathology was excluded from the study. Endometrial samplings by either dilatation and curettage or endometrial biopsy were taken from these patients. The specimen comprised of 84 endometrial curettages and 38 endometrial biopsies. The specimens were processed in automated tissue processor. The sections were stained with Hematoxylin and Eosin stain.

Dating of endometrium was made according to the criteria by Noyes et al. Hyperplasia was classified as sanctioned by WHO (originally proposed by Kurman and Norris). ${ }^{6}$ Data was analysed using the Statistical Package for Social Science (SPSS, version 12) for Windows.

\section{RESULTS}

The age of the patient ranged from 20-74 years. Maximum numbers of patients were in the age group of 40-49 years 48 (39.34\%). Out of 122 patients, 94 (77.05\%) were premenopausal whereas $28(22.95 \%)$ were postmenopausal. The predominant pattern of bleeding was metrorrhagia $47(38.52 \%)$ followed by menorrhagia $37(30.32 \%)$ and postmenopausal bleeding $28(23.0 \%)$. Majority of patients $91(74.59 \%)$ had no history of pain lower abdomen. Histopathological examination showed proliferative endometrium as the predominant finding 32 (26.23\%) followed by simple hyperplasia without atypia 22 (18.03\%). Malignant lesions comprised of 7 (5.74\%) of the cases (Fig. $1 \& 2$ ). The histopathological diagnosis of endometrial biopsy is given in Table 1 .

In women under 30 years of age proliferative endometrium was found in 6/13 (46.15\%) patients and secretory endometrium in $4 / 13$ (30.76\%) patients. Thus no significant pathology was found in this age group. In patients $<40$ years of age malignant lesions were less common compared to patients aged $>40$ years. Out of 7 patients with carcinoma,

Table 2: Histopathological diagnosis according to age group

\begin{tabular}{|c|c|c|c|c|c|c|c|c|c|c|c|}
\hline \multicolumn{12}{|c|}{ Histopathological diagnosis } \\
\hline Age group & $\mathbf{P}$ & SH & $\mathbf{S}$ & DP & I & CA & US & $\mathbf{A}$ & EP & $\mathbf{C E}$ & Total \\
\hline $20-29$ & 6 & 1 & 4 & 0 & 1 & 0 & 0 & 0 & 0 & 1 & 13 \\
\hline $30-39$ & 4 & 3 & 3 & 2 & 1 & 1 & 2 & 0 & 0 & 0 & 16 \\
\hline $40-49$ & 14 & 10 & 7 & 4 & 1 & 2 & 2 & 2 & 3 & 3 & 48 \\
\hline $50-59$ & 7 & 7 & 6 & 2 & 2 & 4 & 3 & 4 & 0 & 4 & 39 \\
\hline $60-69$ & 0 & 1 & 0 & 0 & 0 & 0 & 0 & 0 & 0 & 0 & 1 \\
\hline$>70$ & 1 & 0 & 0 & 0 & 0 & 0 & 1 & 3 & 0 & 0 & 5 \\
\hline Total & 32 & 22 & 20 & 8 & 5 & 7 & 8 & 9 & 3 & 8 & 122 \\
\hline
\end{tabular}


$6(85.71 \%)$ were present in the age group of $>40$ years. Out of 48 patients in the age group of $40-49$ years, $14(29.16 \%)$ patients had proliferative endometrium and $10(20.83 \%)$ had simple hyperplasia without atypia. Endometrial polyp and chronic endometritis (Fig. 3) were also more common in this age group compared to other age groups. Tuberculous endometritis was detected in one patient (Fig. 4). Atrophic endometrium was mostly seen in elderly patients and was the most common finding in postmenopausal bleeding $8 / 28(28.6 \%)$ followed by carcinoma $5 / 28(17.9 \%)$. The histopathological diagnosis of endometrial biopsy according to age is given in Table 2. Carcinoma in postmenopausal women was found to be high compared to those with premenopausal women $(17.9 \%$ vs. $2.12 \%, \mathrm{p}=0.002)$.

Secretory endometrium 16 (51.61\%) was the most common finding in patients with pain lower abdomen followed by chronic endometritis $5(16.12 \%)$. In patients without pain abdomen proliferative endometrium 29 (31.86\%) was predominant finding followed by simple hyperplasia without atypia $20(22.0 \%)$.

\section{DISCUSSION}

Abnormal uterine bleeding without structural pathology occurs in reproductive women of all ages but is more common in adolescent and perimenopausal women. ${ }^{7}$ In perimenopausal years anovulatory cycle is most frequent which in turn causes changes in endometrium, which results in irregular bleeding. ${ }^{8}$ Chronic anovulation is associated with an irregular and unpredictable pattern of bleeding ranging from short cycles with scanty bleeding to prolonged period with irregular heavy loss. Normal bleeding occurs in response to withdrawal of both progesterone and oestradiol. If ovulation doesn't occur then the absence of progesterone results in an absence of secretory change in the endometrium, accompanied by abnormalities in the production of steroid receptors, prostaglandins and other locally active endometrial products. Unopposed estrogen gives rise to persistent proliferative or hyperplastic endometrium and estrogen withdrawal bleeding is characteristically painless and irregular. ${ }^{9}$

In the present study, the most common histopathological finding was proliferative endometrium followed by simple hyperplasia without atypia i.e anovulatory bleeding. In some study endometrial hyperplasia was the most frequent result in women aged 41-50 years. ${ }^{10-12}$ We found simple hyperplasia without atypia in $10(24.6 \%)$ patients in the age group of 40-49 years. Some authors believe disordered proliferative endometrium to be in the same spectrum as hyperplasia, ${ }^{13}$ so that the total number of cases in our study was $14(29.16 \%)$. Our study is also showing agreement with the other studies. ${ }^{10-13}$ In this study most of the cases $91(74.59 \%)$ with this endometrial pattern had no history of lower abdominal pain.

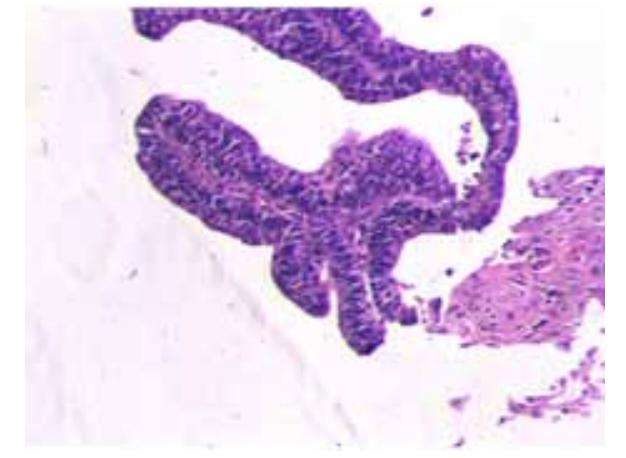

Figure 1: Photomicrograph of adenocarcinoma with squamous differentiation. (HE stain, X100)

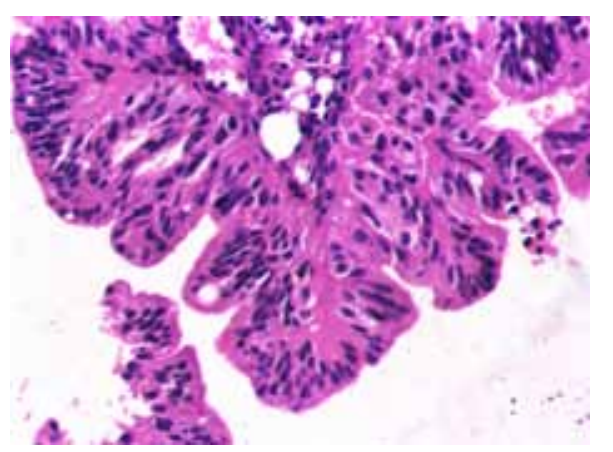

Figure 2: Photomicrograph of endometrial carcinoma, villoglandular variant. (HE stain, X200).

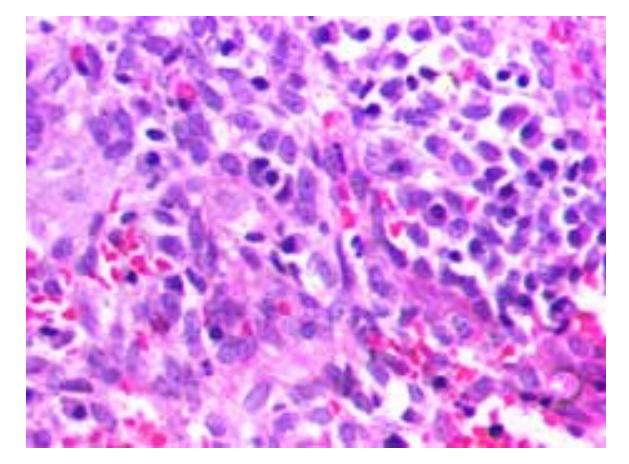

Figure 3: Photomicrograph of chronic endometritis showing plasma cells in stroma. (HE stain, X400).

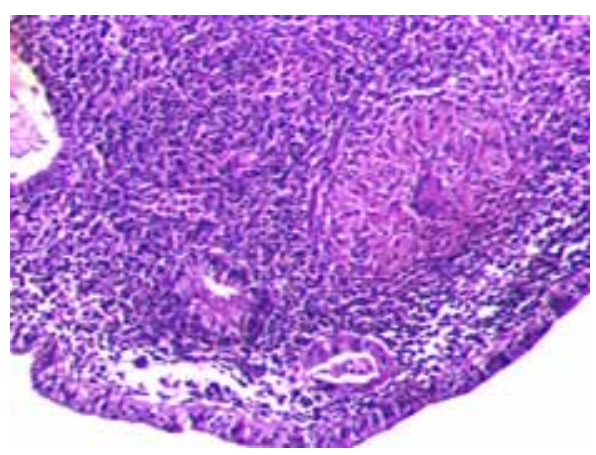

Figure 3: Photomicrograph of tuberculous endometritis showing epitheloid cell granulomas and langhan giant cells. (HE stain, X100). 
Postmenopausal bleeding is frequently associated with an atrophic endometrium. Atrophy of endometrium occurs as a consequence of the prolonged absence of any endogenous or exogenous estrogenic stimulation. The thin atrophic endometrium is susceptible to minor injury and may be responsible for postmenopausal bleeding even in the absence of an identifiable lesion. Superficial large, dilated venules are situated under a thin endometrium which may rupture to cause excessive uterine bleeding. ${ }^{14}$

PMB was most commonly associated with atrophic endometrium in this study, which was $28.6 \%$ of all PMB cases. Malignant neoplasm are generally accepted to be relatively uncommon causes of $\mathrm{PMB}$ with endometrial carcinoma being involved in 7 to $17.7 \%$ patient. ${ }^{7,15-19}$ In our study endometrial carcinoma was diagnosed in $17.90 \%$ of patients similar to the study done in this region. ${ }^{7}$ Carcinoma in postmenopausal women was found to be statistically high compared to those with premenopausal women $(17.9 \%$ vs. $2.12 \%, \mathrm{p}=0.002$ )

\section{CONCLUSION}

Benign lesions or no significant pathology was seen in most patients. Anovulatory bleeding was common especially in premenopausal women. Malignancy in particular was common in patients over 40 years of age. Hence histopathological examination should be done generously in women presenting with AUB especially after the age of 40 years to rule out malignant pathology.

\section{REFERENCES}

1. Munro MG. Abnormal uterine bleeding in the reproductive years: Pathogenesis and clinical investigations. J Am Assoc Gynecol laparos 1999;6:393-416.

2. Albers JR, Hull SK, Wesley RM. Abnormal uterine bleeding. Am Fam Physician 2004;69:1915-26.

3. Beard CM, Hartmann LC, Keeney GL et al. Endometrial cancer in Olmsted country, MN: trends in incidence, risk factors and survival. Ann Epidemiol 2000;10:97-105.

4. Parslov M, Lidegaard O, Klintorp S et al. Risk factors among young women with endometrial cancer: a Danish case-control study. Am J Obstet Gynecol 2000;182:23-9.
5. Spencer CP, Whitehead MI. Endometrial assessment re-visited. Br J Obstet Gynaecol 1999;106:623-32.

6. Kurman RJ, Norris HJ. Endometrium. In Henson DE, Alboressaavedra J (eds): The pathology of incipient neoplasia. Philadelphia: W.B. Saunders;1986. pp265-77.

7. Dangal G: A study of endometrium of patients with abnormal uterine bleeding at Chitwan valley. Kathmandu University Med J $2003 ; 1: 110-12$

8. Todorovic N, Djordjevic V, Antonijevic S. Results of histopathologic findings of endometrial changes in metrorrhagia. Srp Arh Celok Lek 2002;130:386-8.

9. Lumsden M, Norman F. Menstruation and menstrual abnormality. In: Shaw RW, Soutter WP, Stanton SL. Gynaecology 2nd ed Churchil Livingstone Newyork 1997. pp421-37.

10. Vakiani M, Vavilis D, Agorastos T, Stamatopoulos P, Assimaki A, Bontis J. Histopathological findings of the endometrium in patients with dysfunctional uterine bleeding. Clin Exp Obstet Gynecol 1996;23:236-9.

11. Thakur S, Premi HK, Randhawa I, Verma S, Sharma BB. Epidemiological evaluation of excessive and / or irregular uterine bleeding. Indian J Public Health 1993; 37:133-4.

12. Sloboda L, Molnar E, Popovic Z, Zivkovic S. Analysis of pathohistological results from the uterine mucosa 1965-1998 at the gynaecology department in Senta. Med Pregl 1999;52:263-5.

13. Zaino RJ. Endometrial hyperplasia and carcinoma. In: Fox H, Wells M. Haines \& Taylor Obstetrical and Gynaecological Pathology 5th ed. UK: Churchil Livingstone; 2003.pp443-88.

14. Archer DF, McIntyre-seitman K, Wilborn WW et al. Endometrial morphology in asymptomatic postmenopausal women. Am J Obstet Gynecol 1991;165:317-22.

15. Choo YC, Mak KC, Hsu C, Wong TS, Ma HK. Post menopausal uterine bleeding of non organic cause. Obstet Gynecol 1985;66:2258.

16. Lidor A, Ismajorich B, Confino E, David MP. Histopathological findings in 266 women with postmenopausal uterine bleeding. Acta Obstet Gynecol Scand 1986;65:41-3.

17. Escoffery CT, Blake GO, Sargeant LA. Histopathological findings in women with postmenopausal bleeding in Jamaica. West Indian Med J 2002;51;32-5.

18. Gredmark T, Kvint S, Havel G, Mattson LA. Histopathological findings in women with postmenopausal bleeding: $\mathrm{Br} \mathrm{J}$ Obstet Gynaecol 1995; 102:133-6.

19. Danero S, Ricci MG, La Rosa R, Massafra C, Franchi F, Pitino C. Critical review of dilatation and curettage in the diagnosis of malignant pathology of the endometrium. Eur J Gynaecol Oncol $1986 ; 7: 162-5$. 